\title{
A Discourse on Analytical Study of Nearly - Open Sets.
}

\author{
Vidyottama Kumari \\ Research scholar \&Assistant Professor, Deptt. Of Mathematics, R.V.S College OF Engineering \& Technology, \\ Jamshedpur, Jharkhand, INDIA.
}

\begin{abstract}
The aim of this paper is to elaborate the study of some nearly-open sets as p-open, s-open, $\alpha$-open $\& \beta$-open sets \& the associated strongly continuity as well as compactness. Also the inter relationship of these nearly open sets has been discussed.
\end{abstract}

Keywords: $p$ - open set, s-open set, $\alpha$-open set, $\beta$-open set.

\section{Introduction \& Preliminaries:}

The concept of pre open set in topological spaces was introduced in 1982[13]. This set was also considered in [12] and [11]. In 1982, A.S.Mashhour et al [13] have defined the notion of pre open sets. The notion of pre open sets play a significant role in general topology. Pre open sets are also called nearly open and locally dense sets by several authors in the literature. They are not only important in the context of covering properties and decompositions of continuity but also in functional analysis in the context of open mapping theorems and closed graph theorems. The concepts of preclosure and preinterior of a set are also due to A.S.Mashhour et al [13]\&[16]. In 1998, Navalagi [17] has defined pre neighbourhoods, pre-interior point, prelimit point, prederived set and prefrontier of set. The present paper is an attempt to arrive at further results on nearly-open and nearly-closed sets and to study some of its properties.

In the recent years some authors have studied b-open and s-open sets in topological spaces and also other similar concepts.

The concept of pre- open (i.e. p-open), semi open (i.e. s-open), pre-semi open (i.e. $\alpha$-open) and semipre open (i.e. $\beta$-open) sets plays an important role in the research of generalizations of continuity in topological spaces [1]. By using these sets many authors introduced and studied various types of generalizations of continuity [2].

D. Andrijevic introduced notion of semi pre- open sets known as $\beta$-open sets [1]. The modified forms of these sets and generalized continuity were further developed by many mathematicians $[2,5]$.

The concept of compactness is an abstraction of an important property possessed by closed and bounded subsets of the set R of real numbers, known as "Heine-Borel Property" which states that if the union of any family of open intervals in R contains a closed interval $I \subset R$, then that family has a sub family whose union also contains I. In more general spaces than the real line, compactness is concerned with covering the set by open sets.

Compactness is dealt with covering the sets by pre-open sets is named as strong compactness, symbolized as p-compactness due to [18]. Semi compactness was studied by Dorsett [19] , [20]and [21], while the concept of strong compactness is due to Mashhour et al. [18] .Compactness in terms of semi-open sets is known as semi-compactness, in terms of $\alpha$-open sets known as $\alpha$-compactness $\&$ in terms of $\beta$-open sets known as $\beta$ - compactness.

Throughout this paper, spaces $(\mathrm{X}, \mathrm{T})$ and $\left(\mathrm{Y},{ }_{\sigma}\right)$ (or simply $\mathrm{X}$ and $\left.\mathrm{Y}\right)$ always mean topological spaces on which no separation axioms are assumed unless explicitly stated.

If $(\mathrm{X}, \mathrm{T})$ is a topological space and $\mathrm{A} \subseteq \mathrm{X}$, then the notion of the closure of $\mathrm{A} \&$ the interior of A are given as $\mathrm{T}-\mathrm{cl}(\mathrm{A})$ and $\mathrm{T}-\mathrm{int}(\mathrm{A})$ respectively.

Let us recall the following definitions, which are useful in sequel.

\section{Definitions :}

Let $\mathrm{A} \subseteq \mathrm{X}$ where $(\mathrm{X}, \mathrm{T})$ a topological space is, then $\mathrm{A}$ is said to be
a) pre-open(or p-open) if
$\mathrm{A} \subseteq \mathrm{T}-\operatorname{int}(\mathrm{T}-\mathrm{cl}(\mathrm{A}))$.
b) semi- open (or s-open) if
$\mathrm{A} \subseteq \mathrm{T}-\operatorname{cl}(\mathrm{T}-\operatorname{int}(\mathrm{A}))$.
c) pre- semi open(or $\alpha$-open) if $\mathrm{A} \subseteq \mathrm{T}$-int-(T-cl-(T-int(A))).
d) semi -pre open(or $\beta$-open) if $\mathrm{A} \subseteq \mathrm{T}$-cl-(T-int(T-cl(A))).
e) a regular open set if $\mathrm{A}=\mathrm{T}$-int $(\mathrm{T}-\mathrm{cl}(\mathrm{A})$ ).
f) a regular closed set if $\mathrm{A}=\mathrm{T}-\mathrm{cl}(\mathrm{T}-\operatorname{int}(\mathrm{A}))$. 
The semi-closure (resp. pre closure, $\alpha$-closure, semi-pre closure) of a subset A of a space $(X, T)$ is the intersection of all semi-closed( resp. pre closed, $\alpha$-closed, semi-pre -closed) sets that contain A and is denoted by s-cl(A)(res. p-cl(A), $\alpha-\operatorname{cl}(\mathrm{A}), \beta-\operatorname{cl}(\mathrm{A}))$.

\section{Fundamental properties:}

It has been observe that all the concepts of pre, semi, $\alpha \& \beta$ open sets are different from one another. The classes of these sets in a topological space $(X, T)$ are larger than $\mathrm{T}$ and closed under forming arbitrary union.

Let $\mathrm{PO}(\mathrm{X}, \mathrm{T}), \mathrm{SO}(\mathrm{X}, \mathrm{T}), \alpha \mathrm{O}(\mathrm{X}, \mathrm{T}) \& \beta \mathrm{O}(\mathrm{X}, \mathrm{T})$ stand for the classes of p-open, s-open, $\alpha$-open \& $\beta$-open sets respectively in a topological space $(X, T)$. Except $\alpha \mathrm{O}(\mathrm{X}, \mathrm{T})$, in general none of the remaining three forms a topology on X.

However (i) the intersection of a pre- open set and an open set is pre-open,

(ii) the intersection of a semi- open set and an open set is semi-open,

(iii) the intersection of a $\alpha$ - open set and an open set is $\alpha$-open,

(iv)the intersection of $\beta$ - open set and an open set is $\beta$-open.

These concepts are connected as follows:

$$
\begin{aligned}
& \text { In a topological space }(\mathrm{X}, \mathrm{T}) \text {, let } \mathrm{A} \subseteq \mathrm{X} \text {, then } \\
& \begin{aligned}
\mathrm{A} \text { is } \mathrm{T} \text { - closed } \Rightarrow \mathrm{A} \text { is } \alpha \text {-closed } & \Rightarrow \mathrm{A} \text { is s-closed. } \\
& \Rightarrow \mathrm{A} \text { is } \beta \text {-closed. } \\
& \Rightarrow \mathrm{A} \text { is p-closed. }
\end{aligned}
\end{aligned}
$$

The converse implications are not in general true.

In a topological space $(\mathrm{X}, \mathrm{T})$, a subset $\mathrm{A}$ is

(i) Pre-regular open iff $\mathrm{A}^{\mathrm{C}}$ is semi -regular open.

(ii) $\alpha$-regular open iff $\mathrm{A}^{\mathrm{C}}$ is $\beta$-regular open.

In a topological space, a set, being clopen, possess all the above four concepts.

Here we discuss some examples of $\mathrm{p}$ - open, s-open, $\alpha$-open $\& \beta$-open subsets of topological spaces which are useful for our work. These examples also help in understanding other concepts.

\section{Example (1.1):}

Let $\mathrm{X}$ be an infinite set and let $\mathrm{T}$ be the co-finite topology on $\mathrm{X}$. We consider following types of sets:

$\mathrm{A}$ - a finite set, B- an infinite set such that ${ }_{B}{ }^{C}$ is finite and C- an infinite set such that $C^{c}$ is also infinite. Thus we have

$$
\begin{array}{lll}
\mathrm{T}-\operatorname{cl}(\mathrm{A})=\mathrm{A}, & \mathrm{T}-\mathrm{cl}(\mathrm{B})=\mathrm{X}, & \mathrm{T}-\mathrm{cl}(\mathrm{C})=\mathrm{X}, \\
\mathrm{T}-\operatorname{int}(\mathrm{A})=\varnothing, & \mathrm{T}-\operatorname{int}(\mathrm{B})=\mathrm{B}, & \mathrm{T}-\operatorname{int}(\mathrm{C})=\varnothing, \\
\mathrm{T}-\mathrm{cl}(\mathrm{T}-\operatorname{int}(\mathrm{A}))=\varnothing, & \mathrm{T}-\mathrm{cl}(\mathrm{T}-\operatorname{int}(\mathrm{B}))=\mathrm{X}, & \mathrm{T}-\mathrm{cl}(\mathrm{T}-\operatorname{int}(\mathrm{C}))=\varnothing, \\
\mathrm{T}-\operatorname{int}(\mathrm{T}-\mathrm{cl}(\mathrm{A})=\varnothing, & \mathrm{T}-\operatorname{int}(\mathrm{T}-\mathrm{cl}(\mathrm{B})=X, & \mathrm{T}-\operatorname{int}(\mathrm{T}-\mathrm{cl}(\mathrm{A})=X,
\end{array}
$$

$\mathrm{T}-\operatorname{int}(\mathrm{T}-\mathrm{cl}(\mathrm{T}-\operatorname{int}(\mathrm{A}))=\emptyset, \mathrm{T}-\operatorname{int}(\mathrm{T}-\mathrm{cl}(\mathrm{T}-\operatorname{int}(\mathrm{B}))=\mathrm{X}, \mathrm{T}-\operatorname{int}(\mathrm{T}-\mathrm{cl}(\mathrm{T}-\operatorname{int}(\mathrm{C}))=\emptyset$,

$\mathrm{T}-\operatorname{cl}(\mathrm{T}-\operatorname{int}(\mathrm{T}-\mathrm{cl}(\mathrm{A})))=\varnothing, \mathrm{T}-\mathrm{cl}(\mathrm{T}-\operatorname{int}(\mathrm{T}-\mathrm{cl}(\mathrm{B})))=\mathrm{X}, \mathrm{T}-\mathrm{cl}(\mathrm{T}-\mathrm{int}(\mathrm{T}-\mathrm{cl}(\mathrm{C})))=\mathrm{X}$, Thus we see that

(i) $\quad \mathrm{A}$ is neither p-open nor s-open, nor $\alpha$-open, nor $\beta$-open.

(ii) $\mathrm{B}$ is p-open, s-open, $\alpha$-open, and $\beta$-open. This means that $\mathrm{B}$ is $\mathrm{p}$-closed, s- closed, $\alpha$-closed and $\beta$ closed.

(iii) $\quad \mathrm{C}$ is p-open and $\beta$-open but it is neither s-open nor $\alpha$-open. This means that $\mathrm{C}$ is also p-closed and $\beta$ closed.

\section{Example (1.2):}

We consider the topological space $(\mathrm{X}, \mathrm{T})$ where $\mathrm{X}=\{\mathrm{a}, \mathrm{b}, \mathrm{c}, \mathrm{d}\} \quad$ and $\mathrm{T}=$ $\{\varphi,\{a\},\{b\},\{a, b\},\{a, c\},\{a, b, c\},\{a, b, d\}, X\}$ $\Phi,\{c\},\{d\},\{b, d\},\{c, d\},\{a, c, d\},\{b, c, d\}, X$.

then the closed subsets of $X$ are:

From the above list it follows that

(i) $\quad$-open subsets of $X$ are :

$\varphi,\{a\},\{b\},\{a, b\},\{a, c\},\{a, b, c\},\{a, b, d\}, X$.

p-closed subsets of $X$ are:

$\varphi,\{c\},\{d\},\{b, d\},\{c, d\},\{a, c, d\},\{b, c, d\}, X$.

(ii) $\mathrm{s}$ - open subsets of $\mathrm{X}$ are : 
$\varphi,\{a\},\{b\},\{a, b\},\{a, c\},\{a, d\},\{b, d\},\{a, b, c\},\{a, b, d\},\{a, c, d\}, X$.

s-closed subsets of $X$ are:

$\varphi,\{b\},\{c\},\{d\},\{a, c\},\{b, c\},\{b, d\},\{c, d\},\{a, c, d\},\{b, c, d\}, X$.

(iii) $\alpha$ - open subsets of $X$ are :

$\varphi,\{a\},\{b\},\{a, b\},\{a, c\},\{a, b, c\},\{a, b, d\}, X$.

$\alpha$-closed subsets of $X$ are:

$\varphi,\{c\},\{d\},\{b, d\},\{c, d\},\{a, c, d\},\{b, c, d\}, X$.

(iv) $\beta$ - open subsets of $X$ are :

$\varphi,\{a\},\{b\},\{a, b\},\{a, c\},\{a, d\},\{b, d\},\{a, b, c\},\{a, b, d\},\{a, c, d\}, X$.

$\beta$-closed subsets of $X$ are:

$\varphi,\{b\},\{c\},\{d\},\{a, c\},\{b, c\},\{b, d\},\{c, d\},\{a, c, d\},\{b, c, d\}, X$.

\section{Observations \& Results(1.3):}

From the above examples it follows that the concepts of p-open, s-open, $\alpha$-open and $\beta$-open sets are independent, they may coincide in some cases.

* Topologies determining the same class of $\alpha$ sets, also determine the same class of $\beta$ sets and vice- versa.

$*$

* Every $\alpha$-open set is p-open as well as s-open.

* The $\alpha$-sets with respect to a given topology are exactly those sets which are difference between an open set and a nowhere dense set.

* A topology is an $\alpha$-topology if and only if all nowhere dense sets are closed.

* In a topological space $(X, T)$, let $S \subseteq X$, then the following are the relations among s-int, $\mathrm{p}$-int, $\beta$-int of $\mathrm{S}$ and s- closure, $\mathrm{p}$-closure $\& \beta$-closure of $\mathrm{S}$ :

(i) $\quad \mathrm{s}-\mathrm{cl}(\mathrm{s}-$ int $\mathrm{S})=\mathrm{s}-$ int $\mathrm{S} \cup \operatorname{int}(\operatorname{cl}($ int $\mathrm{S}))$.

(ii) $\quad \mathrm{p}-\mathrm{cl}(\mathrm{p}$-int $\mathrm{S})=\mathrm{p}$-int $\mathrm{S} \cup \operatorname{cl}($ int $\mathrm{S})$.

(iii) $\quad \beta-\operatorname{cl}(\beta$-int $S)=\beta$-int $(\beta$-cl $S)$.

(iv) $\quad \operatorname{int}(\mathrm{s}-\mathrm{cl} \mathrm{S})=\mathrm{p}-\operatorname{int}(\mathrm{cl} \mathrm{S})=\mathrm{p}-\operatorname{int}(\mathrm{s}-\mathrm{cl} \mathrm{S})=\mathrm{s}-\mathrm{cl}(\mathrm{p}-$ int $S)=\operatorname{int}(\mathrm{cl} \mathrm{S})$.

(v) $\quad \operatorname{int}(\mathrm{p}-\mathrm{cl} \mathrm{S})=\operatorname{s-cl}($ int $\mathrm{S})=\beta-\mathrm{cl}($ int $\mathrm{S})=\operatorname{int}-\beta(\mathrm{cl} \mathrm{S})=\operatorname{int}(\operatorname{cl}($ int $\mathrm{S})){ }^{*}$ In a topological space $(\mathrm{X}, \mathrm{T})$ if $\mathrm{A}=$ $\mathrm{U} \cap \mathrm{B}$ where $\mathrm{U}$ is open and $\mathrm{B}$ is $\beta$-closed, then $\alpha$-int $(\mathrm{A})=$ int-A.

Also p-int(s-int $(S))=\alpha$-int( $S), S \subseteq X$.

\section{Comparative study of strongly p-continuity, s-continuity, $\alpha$-continuity \&}

\section{Definition (2.1):} B-continuity in topological spaces.

A mapping $\mathrm{f}:(\mathrm{X}, \mathrm{T}) \rightarrow(\mathrm{Y}, \sigma)$ from a topological space $(\mathrm{X}, \mathrm{T})$ to another topological

Space $(\mathrm{Y}, \sigma)$ is said to be strongly $\quad \boldsymbol{K}$-continuous iff $\mathrm{f}^{-1}(\sigma-\operatorname{int})=\boldsymbol{K}-\operatorname{int}\left(\mathrm{f}^{-1}(\mathrm{~A})\right) ; \forall \mathrm{A} \subseteq \mathrm{Y}$, where $\boldsymbol{K}=\mathrm{p}, \mathrm{s}, \alpha \& \beta$ sets.

Remark (2.2):

The above fact enables us to draw the conclusion as:

If $\mathrm{f}:(\mathrm{X}, \mathrm{T}) \rightarrow(\mathrm{Y}, \sigma)$ be a mapping defined on $(\mathrm{X}, \mathrm{T})$ into $(\mathrm{Y}, \sigma)$, then

$\mathrm{f}$ is $\boldsymbol{K}$-continuous on $\mathrm{X} \Rightarrow \mathrm{f}$ is continuous .

Now, the following theorem appears as the characteristic property of strongly

$\boldsymbol{K}$-continuity :

Theorem (2.3):

Let A mapping $\mathrm{f}:(\mathrm{X}, \mathrm{T}) \rightarrow(\mathrm{Y}, \sigma)$ from a topological space $(\mathrm{X}, \mathrm{T})$ to another topological space $(\mathrm{Y}, \sigma)$ is $\boldsymbol{K}$-continuous on $\mathrm{X}$ iff $\mathrm{f}^{-1}(\sigma-\mathrm{cl}(\mathrm{A}))=\beta$ - $\mathrm{cl}\left(\mathrm{f}^{1}(\mathrm{~A})\right)$, for every subset $\mathrm{A}$ of $\mathrm{Y}$, where $\boldsymbol{K}=\mathrm{p}, \mathrm{s}, \alpha$ $\& \beta$. 


\section{Proof:}

Suppose that $\mathrm{f}$ is strongly $\boldsymbol{K}$-continuous on $\mathrm{X}$, then $\mathrm{f}^{-1}(\sigma-\operatorname{int} \mathrm{A})=K_{-}-\operatorname{int}\left(\mathrm{f}^{-1}(\mathrm{~A}) ; \forall \mathrm{A} \subseteq \mathrm{Y}\right.$.

Thus, for every $\mathrm{A} \subseteq \mathrm{Y}$, we have

$$
\begin{aligned}
\mathrm{f}^{-1}(\sigma-\operatorname{cl}(\mathrm{A})) & =\mathrm{f}^{-1}\left\{\left(\sigma-\operatorname{int}\left(\mathrm{A}^{\mathrm{C}}\right)\right\}^{\mathrm{C}}\right. \\
& =\left\{\mathrm{f}^{-1}\left(\sigma-\operatorname{int}\left(\mathrm{A}^{\mathrm{C}}\right)\right\}^{\mathrm{C}}\right. \\
& =\left\{\boldsymbol{K}-\operatorname{int}\left(\mathrm{f}^{-1}\left(\mathrm{~A}^{\mathrm{C}}\right)\right)\right\}^{\mathrm{C}}=\left\{\boldsymbol{K}-\operatorname{int}\left(\mathrm{f}^{-1}(\mathrm{~A})^{\mathrm{C}}\right\}^{\mathrm{C}}\right. \\
& =\boldsymbol{K}-\operatorname{cl}\left\{\left(\mathrm{f}^{-1}(\mathrm{~A})\right)^{\mathrm{C}}\right\}^{\mathrm{C}}=\boldsymbol{K}-\operatorname{cl}\left(\mathrm{f}^{-1}(\mathrm{~A})\right) .
\end{aligned}
$$

Conversely, suppose that $\mathrm{f}^{-1}(\sigma-\operatorname{int} \mathrm{A})=\boldsymbol{K}_{\text {- int }}\left(\mathrm{f}^{-1}(\mathrm{~A}) ; \forall \mathrm{A} \subseteq \mathrm{Y}\right.$.

Then for every $\mathrm{A} \subseteq \mathrm{Y}$, we have

$\mathrm{f}^{-1}(\sigma-$ int $\mathrm{A})=\mathrm{f}^{-1}\left\{\left(\sigma-\operatorname{cl}\left(\mathrm{A}^{\mathrm{C}}\right)\right\}^{\mathrm{C}}\right.$

$$
\begin{aligned}
= & \left\{\mathrm{f}^{-1}\left(\sigma-\operatorname{cl}\left(\mathrm{A}^{\mathrm{C}}\right)\right\}^{\mathrm{C}}\right. \\
= & \left\{\boldsymbol{K}-\operatorname{cl}\left(\mathrm{f}^{-1}\left(\mathrm{~A}^{\mathrm{C}}\right\}^{\mathrm{C}}\right.\right. \\
= & \boldsymbol{K}-\operatorname{int}\left\{\left(\mathrm{f}^{-1}\left(\mathrm{~A}^{\mathrm{C}}\right\}^{\mathrm{C}}\right.\right. \\
= & \boldsymbol{K} \text {-int }\left\{\left(\mathrm{f}^{-1}\left(\mathrm{~A}^{\mathrm{C}}\right)^{\mathrm{C}}\right\}\right. \\
= & \boldsymbol{K}-\operatorname{int}\left(\mathrm{f}^{-1}(\mathrm{~A}) .\right.
\end{aligned}
$$

Hence, $\mathrm{f}$ is strongly $\boldsymbol{K}$-continuous on $\mathrm{X}$.

\section{Corollary(2.4):}

If $\mathrm{f}:(\mathrm{X}, \mathrm{T})$ is strongly $\boldsymbol{K}$-continuous on $\mathrm{X}$, then

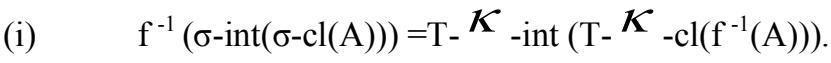

$\mathrm{f}^{-1}(\sigma-\operatorname{cl}(\sigma-\operatorname{int}(\mathrm{A})))=\mathrm{T}-\boldsymbol{K}_{\mathrm{cl}}\left(\mathrm{T}-\boldsymbol{K}_{-i n t}\left(\mathrm{f}^{-1}(\mathrm{~A})\right)\right), \forall A \subseteq Y$.

Theorem (2.5):

If $f:(X, T) \rightarrow(Y, \sigma)$ is strongly $p$ - continuous on $X$, then

(i) $\quad \mathrm{f}^{-1}(\mathrm{~A})$ is $\mathrm{p}$ - open in $\mathrm{X}$ whenever $\mathrm{A}$ is $\mathrm{p}$-open in $\mathrm{Y}$.

(ii) $\quad \mathrm{f}^{-1}(\mathrm{~A})$ is $\mathrm{b}$ - open in $\mathrm{X}$ whenever $\mathrm{A}$ is s-open in $\mathrm{Y}$.

\section{Proof:}

(i) We have, $\mathrm{A}$ is p-open in $\mathrm{Y}$.

$\Rightarrow \mathrm{A} \subseteq \sigma$-int $(\sigma-\operatorname{cl}(\mathrm{A})$

$\Rightarrow \mathrm{f}^{-1}(\mathrm{~A}) \subseteq \mathrm{f}^{-1}(\sigma-\operatorname{int}(\sigma-\operatorname{cl}(\mathrm{A})))$.

$$
=\mathrm{T}-\mathrm{p} \operatorname{int}\left(\mathrm{T}-\mathrm{p}-\mathrm{cl}\left(\mathrm{f}^{-1}(\mathrm{~A})\right)\right. \text {. }
$$

$\Rightarrow \mathrm{f}^{-1}(\mathrm{~A})$ is $\mathrm{p}$-open in $\mathrm{X}$.

(ii)We have, $\mathrm{A}$ is s-open in $\mathrm{Y}$.

$$
\begin{aligned}
\Rightarrow \mathrm{A} \subseteq \sigma-\operatorname{cl}(\sigma-\operatorname{int}(\mathrm{A}) & \\
\Rightarrow \mathrm{f}^{-1}(\mathrm{~A}) \subseteq \mathrm{f}^{-1}(\sigma-\operatorname{cl}(\sigma-\operatorname{int}(\mathrm{A}))) & =\mathrm{T}-\mathrm{p}-\mathrm{cl}\left(\mathrm{T}-\mathrm{p}-\operatorname{int}\left(\mathrm{f}^{-1}(\mathrm{~A})\right) .\right.
\end{aligned}
$$

$\Rightarrow \mathrm{f}^{-1}(\mathrm{~A})$ is b-open in $\mathrm{X}$.

(since for a subset $\mathrm{A}$ of a topological space $\mathrm{X}$ the following are equivalent :
(a) $\quad \mathrm{A}$ is b-open.

$\mathrm{A} \subset \mathrm{p}-\mathrm{cl}(\mathrm{p}$-int A) ; D.Anderjevic : on b-open sets, proposition(2.1))

, Mat Vesnik 48(1996)p.p.59-64.

Theorem (2.6):

$$
\text { If } f:(X, T) \rightarrow(Y, \sigma) \text { is strongly s- continuous on } X \text {, then }
$$

(i) $\quad \mathrm{f}^{-1}(\mathrm{~A})$ is semi-pre open in $\mathrm{X}$ whenever $\mathrm{A}$ is $\mathrm{p}$-open in $\mathrm{Y}$.

(ii) $\mathrm{f}^{-1}(\mathrm{~A})$ is semi- open in $\mathrm{X}$ whenever $\mathrm{A}$ is s-open in $\mathrm{Y}$.

Proof:

(i) We have, $\mathrm{A}$ is p- open in $\mathrm{Y}$.

$$
\begin{aligned}
& \Rightarrow \mathrm{A} \subseteq \sigma-\operatorname{int}(\sigma-\operatorname{cl}(\mathrm{A}) \\
& \Rightarrow \mathrm{f}^{1}(\mathrm{~A}) \subseteq \\
& \quad \mathrm{f}^{-1}(\sigma-\operatorname{int}(\sigma-\operatorname{cl}(\mathrm{A}))) . \\
& =\mathrm{T}-\mathrm{s}-\operatorname{int}\left(\mathrm{T}-\mathrm{s}-\mathrm{cl}\left(\mathrm{f}^{-1}(\mathrm{~A})\right) .\right.
\end{aligned}
$$

$\Rightarrow \mathrm{f}^{-1}(\mathrm{~A})$ is semi-pre open in $\mathrm{X}$.

(ii)We have, $\mathrm{A}$ is s-open in $\mathrm{Y}$.

$$
\begin{aligned}
& \Rightarrow \mathrm{A} \subseteq \sigma-\operatorname{cl}(\sigma-\operatorname{int}(\mathrm{A}) \\
& \Rightarrow \mathrm{f}^{-1}(\mathrm{~A}) \subseteq \mathrm{f}^{-1}(\sigma-\mathrm{cl}(\sigma-\operatorname{int}(\mathrm{A}))) . \\
& =\mathrm{T}-\mathrm{s}-\mathrm{cl}\left(\mathrm{T}-\mathrm{s}-\operatorname{int}\left(\mathrm{f}^{-1}(\mathrm{~A})\right) .\right.
\end{aligned}
$$

$\Rightarrow \mathrm{f}^{-1}(\mathrm{~A})$ is semi-open in $\mathrm{X}$. 
(since for a subset $\mathrm{A}$ of a topological space $\mathrm{X}$ the following are equivalent :

(i) (a) A is semi-pre-open.

(b) $\mathrm{A} \subseteq$ s-int(s-cl(A) ; REMARK 2 D.Anderjevic : on b-open sets, Mat Vesnik 48(1996)p.p.59-64.

Or

(ii)(a) $\mathrm{A}$ is semi open .

(b) A $\subseteq$ s-cl(s-int(A);REMARK 2, D.Anderjevic : on b-open sets, Mat Vesnik 48(1996)p.p.59-64.)

Theorem (2.7):

If $\mathrm{f}:(\mathrm{X}, \mathrm{T}) \rightarrow(\mathrm{Y}, \sigma)$ is strongly $\alpha$ - continuous on $\mathrm{X}$, then

(i) $\quad \mathrm{f}^{-1}(\mathrm{~A})$ is pre open in $\mathrm{X}$ whenever $\mathrm{A}$ is $\mathrm{p}$-open in $\mathrm{Y}$.

(ii) $\quad \mathrm{f}^{-1}(\mathrm{~A})$ is semi- open in $\mathrm{X}$ whenever $\mathrm{A}$ is s-open in $\mathrm{Y}$.

Proof:

(i) We have, $\mathrm{A}$ is p- open in $\mathrm{Y}$.

$\Rightarrow \mathrm{A} \subseteq \sigma-\operatorname{int}(\sigma-\operatorname{cl}(\mathrm{A})$.

$\Rightarrow \mathrm{f}^{-1}(\mathrm{~A}) \subseteq \mathrm{f}^{-1}(\sigma-\operatorname{int}(\sigma-\operatorname{cl}(\mathrm{A})))$.

$=\mathrm{T}-\alpha-\operatorname{int}\left(\mathrm{T}-\alpha-\mathrm{cl}\left(\mathrm{f}^{-1}(\mathrm{~A})\right)=\mathrm{T}-\operatorname{int}\left(\mathrm{T}-\operatorname{cl}\left(\mathrm{f}^{-1}(\mathrm{~A})\right)\right.\right.$

$\Rightarrow \mathrm{f}^{-1}(\mathrm{~A})$ is pre open in $\mathrm{X}$.

(ii)We have, $\mathrm{A}$ is s-open in $\mathrm{Y}$.

$$
\begin{aligned}
& \Rightarrow \mathrm{A} \subseteq \sigma-\operatorname{cl}(\sigma-\operatorname{int}(\mathrm{A}) \\
& \Rightarrow \mathrm{f}^{-1}(\mathrm{~A}) \subseteq \mathrm{f}^{-1}(\sigma-\mathrm{cl}(\sigma-\operatorname{int}(\mathrm{A}))) . \\
& \quad=\mathrm{T}-\alpha-\operatorname{cl}\left(\mathrm{T}-\alpha-\operatorname{int}\left(\mathrm{f}^{-1}(\mathrm{~A})\right)=\mathrm{T}-\operatorname{cl}\left(\mathrm{T}-\operatorname{int}\left(\mathrm{f}^{-1}(\mathrm{~A})\right)\right.\right. \\
& \left.\Rightarrow \mathrm{f}^{-1}(\mathrm{~A}) \text { is semi }- \text { open(s-open }\right) \text { in } \mathrm{X} .
\end{aligned}
$$

(since for a subset $\mathrm{A}$ of a topological space $\mathrm{X}$ the following exists

$\mathrm{T}-\alpha$-cl $(\mathrm{T}-\alpha$-int $(\mathrm{A})=\mathrm{T}-\mathrm{cl}(\mathrm{T}-\mathrm{int}(\mathrm{A}))$

$\& \mathrm{~T}-\alpha-\operatorname{int}(\mathrm{T}-\alpha-\mathrm{cl}(\mathrm{A}))=\mathrm{T}-\mathrm{int}(\mathrm{T}-\mathrm{cl}((\mathrm{A}))$,D.Andrijevic, some properties of the topology of $\alpha$ - sets , Mat ,Vesnik 36 (1984),p.p 1-10).

\section{Theorem(2.8):}

If $\mathrm{f}:(\mathrm{X}, \mathrm{T}) \rightarrow(\mathrm{Y}, \sigma)$ is strongly $\beta$ - continuous on $\mathrm{X}$, then

the following results hold good:

(a) If $\mathrm{A}$ is p-open in $\mathrm{Y}$, then $\mathrm{A} \subseteq \sigma$-int $\sigma$-cl(A).

$$
\begin{array}{ll}
\Rightarrow & \mathrm{f}^{-1}(\mathrm{~A}) \subseteq\left(\mathrm{f}^{-1}(\sigma-\operatorname{int} \sigma-\mathrm{cl}(\mathrm{A})) .\right. \\
\Rightarrow & \left.\mathrm{f}^{-1}(\mathrm{~A}) \subseteq \beta \text {-int } \beta \text {-cl }\left(\mathrm{f}^{-1} \mathrm{~A}\right)\right) \ldots .
\end{array}
$$

Now the following cases arise:

$\left(a_{1}\right) \quad$ When $(X, T)$ is extremely disconnected i.e. T-cl( $\left.U\right)$ is open for every open subset $U$ of $X$, we have SPO $(\mathrm{X}, \mathrm{T})=\mathrm{PO}(\mathrm{X}, \mathrm{T})$ and hence from $(\mathrm{I})$

$$
\left.\Rightarrow \quad \mathrm{f}^{-1}(\mathrm{~A}) \subseteq \beta \text {-int } \beta \text {-cl }\left(\mathrm{f}^{-1} \mathrm{~A}\right)\right)=\mathrm{p} \text {-int } \mathrm{p} \text {-cl }\left(\mathrm{f}^{-1}(\mathrm{~A})\right) .
$$

$\left(a_{2}\right) \quad$ When $(X, T)$ is strongly irresolvable i.e. every open subspace of $(X, T)$ is irresolvable i.e. every open subspace of $(X, T)$ has no two disjoint subsets, we have $\mathrm{SPO}(\mathrm{X}, \mathrm{T})=\mathrm{SO}(\mathrm{X}, \mathrm{T})$ and so from (I)

$\mathrm{f}^{-1}(\mathrm{~A}) \subseteq \beta$-int $\beta$-cl $\left.\left(\mathrm{f}^{-1} \mathrm{~A}\right)\right)=\mathrm{s}$-int s-cl $\left(\mathrm{f}^{-1}(\mathrm{~A})\right)$.

$\Rightarrow \quad \mathrm{f}^{-1}(\mathrm{~A})$ is also $\beta$-open.

(b) If $\mathrm{A}$ is s-open in $\mathrm{Y}$, then $\mathrm{A} \subseteq \sigma$-cl $\sigma$-int $(\mathrm{A})$.

$$
\begin{gathered}
\Rightarrow \quad \mathrm{f}^{-1}(\mathrm{~A}) \subseteq \mathrm{f}^{-1}(\sigma-\mathrm{cl} \sigma \text {-int }(\mathrm{A})) . \\
\left.\Rightarrow \quad \mathrm{f}^{-1}(\mathrm{~A}) \subseteq \beta \text {-cl } \beta \text {-int }\left(\mathrm{f}^{-1} \mathrm{~A}\right)\right)
\end{gathered}
$$

Here the following cases arise:

$\left(b_{1}\right) \quad$ When $(\mathrm{X}, \mathrm{T})$ is extremely disconnected, we have

$\mathrm{SPO}(\mathrm{X}, \mathrm{T})=\mathrm{PO}(\mathrm{X}, \mathrm{T})$ and hence from $(\mathrm{II})$

$\mathrm{f}^{1}(\mathrm{~A}) \subseteq \beta$-cl $\beta$-int $\left.\left(\mathrm{f}^{-1} \mathrm{~A}\right)\right)=\mathrm{p}-\operatorname{cl} \mathrm{p}-\operatorname{int}\left(\mathrm{f}^{-1}(\mathrm{~A})\right)$.

$\Rightarrow \quad \mathrm{f}^{-1}(\mathrm{~A})$ is also b-open.

$\left(b_{2}\right)$ When $(X, T)$ is strongly irresolvable, we have $\mathrm{SPO}(\mathrm{X}, \mathrm{T})=\mathrm{SO}(\mathrm{X}, \mathrm{T})$ and so from (II)

$\mathrm{f}^{-1}(\mathrm{~A}) \subseteq \beta$-cl $\beta$-int $\left.\left(\mathrm{f}^{-1} \mathrm{~A}\right)\right)=\mathrm{s}-\mathrm{cl} \mathrm{s}$-int $\left(\mathrm{f}^{-1}(\mathrm{~A})\right)$.

$\Rightarrow \quad \mathrm{f}^{-1}(\mathrm{~A})$ is also s-open.

Here $\mathrm{SO}(\mathrm{X}, \mathrm{T}), \mathrm{PO}(\mathrm{X}, \mathrm{T}) \& \mathrm{SPO}(\mathrm{X}, \mathrm{T})$ stand for the class of semi-open, pre-open \& semi -pre open subsets of $(\mathrm{X}, \mathrm{T})$ respectively. 


\section{Analytical study of p-compact, s-compact, $\alpha$-compact $\& \beta$-compact spaces.}

All the concepts of p-compact, s-compact, $\alpha$-compact, $\beta$-compact spaces are fundamental and useful in the sense that they open a new horizon in the space of Mathematics. These various types of compactness is based on the concept of possible coverings of nearly open sets i.e. $p, s, \alpha$ and $\beta$ open sets in a topological space.

Definitions (3.1):

Let $(\mathrm{X}, \mathrm{T})$ be a topological space and $\mathrm{A} \subseteq \mathrm{X}$. Let $\mu$ be a collection of subset of $\mathrm{X}$ such that $A \subseteq \bigcup \mu$. Then $\mu$ is called $\kappa$-open cover of A if $\mu \subseteq \kappa O(X, T) \quad \kappa=\mathrm{p}, \mathrm{s}, \alpha \& \beta$. The above definitions can be extended to $\mathrm{X}$ if $\mathrm{X}=\bigcup \mu$

\section{$K$-compact topological spaces.}

A topological space $(\mathrm{X}, \mathrm{T})$ is said to be $\boldsymbol{K}$-compact or strongly compact if every $\boldsymbol{K}$-open cover of $\mathrm{X}$ has a finite sub cover of the same type.

A subspace of a topological space, which is $\mathcal{K}$-compact as a topological space in its own rights is said to be $\boldsymbol{K}$-compact subspace. finite sub cover.

A subset $\mathrm{A}$ of a topological space $(\mathrm{X}, \mathrm{T})$ is said to be $\boldsymbol{K}$ - compact if every $\mathrm{T}-\boldsymbol{K}$-open cover of $\mathrm{A}$ has a

Theorem (3.2):

A subspace $\left(\mathrm{A}, \mathrm{T}_{\mathrm{A}}\right)$ of a topological space $(\mathrm{X}, \mathrm{T})$, where $\mathrm{A}$ is a $\mathrm{T}$-semi-open subset of $\mathrm{X}$, is strongly compact space iff $\mathrm{A}$ is strongly compact in $(\mathrm{X}, \mathrm{T})$.

$$
\text { Or }
$$

For a semi open set $\mathrm{A}$ in a topological space $(\mathrm{X}, \mathrm{T})$, let $\left(\mathrm{A}, \mathrm{T}_{\mathrm{A}}\right)$ be a subspace. $\mathrm{A}$ is $\mathrm{p}$-compact w.r.t. the topology $\mathrm{T}$ iff $\mathrm{A}$ is p-compact w.r.t. the topology $\mathrm{T}_{\mathrm{A}}$.

Proof:

Let $(\mathrm{X}, \mathrm{T})$ be a topological space and $\mathrm{A}$ be a semi-open subset of $\mathrm{X}$.

i.e. $\mathrm{A} \subseteq \operatorname{cl}(\operatorname{int}(\mathrm{A}))$.

Let $\left(\mathrm{A}, \mathrm{T}_{\mathrm{A}}\right)$ be a subspace of $(\mathrm{X}, \mathrm{T})$.

Necessity: Suppose that A is $\mathrm{p}$-compact w.r.t. the topology T.

Let $\left\{H_{i}\right\}_{i \in \Delta}$ be a $\mathrm{T}_{\mathrm{A}}$-pre open cover of A so that $\mathrm{A} \subset \bigcup_{i} H_{i}$.

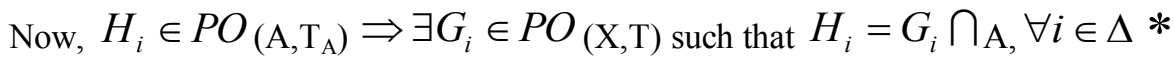

$$
\begin{aligned}
\Rightarrow H_{i} & \subset G_{i}, \forall i \in \Delta \\
& \Rightarrow \bigcup_{i} H_{i} \subset \bigcup_{i} G_{i}, \forall i \in \Delta \\
& \Rightarrow \mathrm{A} \subset \bigcup_{i} H_{i} \subset \bigcup_{i} G_{i} \\
& \Rightarrow\left\{G_{i}\right\}_{i \in \Delta} \quad \text { is T -pre - open cover of A which is p- }
\end{aligned}
$$

compact w.r.t. the topology T.

$\Rightarrow\left\{G_{i}\right\}_{i \in \Delta}$ must be reducible to a finite sub cover say

$\left\{G_{i r}: r=1,2,3,4, \ldots \ldots . . n\right\}$

$$
\begin{aligned}
& \Rightarrow \mathrm{A} \subset \bigcup_{r=1}^{n} G_{i r} \\
& \Rightarrow \mathrm{A} \cap \mathrm{A} \subset \mathrm{A} \cap\left(\bigcup_{r=1}^{n} G_{i r}\right) \\
& \Rightarrow \mathrm{A} \subset \bigcup_{r=1}^{n}\left(\mathrm{~A} \cap G_{i r}\right) . \\
& \Rightarrow \mathrm{A} \subset \bigcup_{r=1}^{n} H_{i r} \\
& \Rightarrow\left\{H_{i r}\right\}_{r=1,2,3, \ldots . . n} \text { is a } \mathrm{T}_{\mathrm{A}} \text {-pre }
\end{aligned}
$$

-open cover of

A . 
Starting from an arbitrary $\mathrm{T}_{\mathrm{A}}$-pre open cover $\left\{H_{i}\right\}_{i \in \Delta}$ of $\mathrm{A}$, we are able to show that this cover is reducible to a finite sub cover $\left\{H_{i r}\right\}_{r=1,2,3, \ldots . . n}$ of A, meaning thereby A is p-compact w.r.t. $\mathrm{T}_{\mathrm{A}}$.

\section{Sufficiency:}

Suppose that $\mathrm{A}$ is $\mathrm{p}$-compact w.r.t. the topology $\mathrm{T}_{\mathrm{A}}$.

Let $\left\{G_{i}\right\}_{i \in \Delta}$ be a T-pre open cover of A so that $\mathrm{A} \subset \bigcup_{i} G_{i}$.

Now,

$$
\begin{aligned}
\mathrm{A} \subset \bigcup_{i} G_{i} & \Rightarrow \mathrm{A} \cap \mathrm{A} \subset \mathrm{A} \cap\left(\bigcup_{i} G_{i}\right) \\
& \Rightarrow A \subset \bigcup_{i}\left(A \cap G_{i}\right) \\
& \Rightarrow A \subset \bigcup_{i}\left(H_{i}\right) \quad\left(\because H_{i}=A \cap G_{i}\right)
\end{aligned}
$$

Since, $\mathrm{G}_{\mathrm{i}} \in \mathrm{PO}(\mathrm{X}, \mathrm{T}) \& \mathrm{~A} \in \mathrm{SO}(\mathrm{X}, \mathrm{T})$, hence, $H_{i}=A \cap G_{i}$ for every $i \in \Delta$, is $\mathrm{T}_{\mathrm{A}}$-pre-open set in $\left(\mathrm{A}, \mathrm{T}_{\mathrm{A}}\right)$.

Combining the above facts, obviously $\left\{H_{i}\right\}_{i \in \Delta}$ is a $\mathrm{T}_{\mathrm{A}}$-pre-open cover of $\mathrm{A}$ which is p-compact w.r.t. the topology $\mathrm{T}_{\mathrm{A}}$. Consequently this cover $\left\{H_{i}\right\}_{i \in \Delta}$ must be reducible to a finite sub cover, say $\left\{H_{i r}\right\}_{r=1,2, \ldots \ldots \ldots . . n}$

This means that $A \subset \bigcup_{r=1}^{n} H_{i_{r}}=\bigcup_{r=1}^{n}\left(A \cap G_{i_{r}}\right)$

$$
\begin{aligned}
& \Rightarrow A \subset \bigcup_{r=1}^{n} G_{i r} \\
& \Rightarrow\left\{G_{i r}\right\}_{r=1,2,3, \ldots . . n} \text { is a finite sub cover of the cover }\left\{G_{i}\right\}_{i \in \Delta}
\end{aligned}
$$

for A.

Starting from an arbitrary T- pre- open cover of A, we are able to claim that pre- open cover is rediucible to a finite sub - cover, meaning there by A is p- compact w.r.t. the topology T.

Hence, the theorem.

Note: the star notation used in the theorem is now clarified as :

* Lemma (1.2)(a), as mentioned in "On $\mathrm{P}_{3}$-Para compact spaces",Khalid Al-Zoubi and Samer Al -Ghour, International Journal of Mathematical Sciences, Volume 2007, Article ID80697,12 pages.doi:1155/2007/80697.

\section{Observations:}

1. If $A \& Y$ are semi open sets in a space $(X, T)$ such that $A \subseteq Y$, then $A \in S O\left(Y, T_{Y}\right)$. subspace of $(X, T)$.

So the above theorem enables us to states that $\mathrm{A}$ is $\mathrm{p}$-compact subspace of $\left(\mathrm{Y}, \mathrm{T}_{\mathrm{Y}}\right)$ iff $\mathrm{A}$ is $\mathrm{p}$-compact

Such a circumstance provides the opportunity to state that "strong compactness is an absolute property for the chain of semi-open sets by inclusion relation ".

We can then restate as:

"A semi-open subset A of a topological space (X,T) is p-compact iff each pre-open covering of A is reducible to a finite sub covering ".

2. Strongly compactness is hereditary with respect to semi-open sets.

3. Strongly compactness is not a hereditary property.

Theorem(3.3) :

If a pre-open subset $\mathrm{Y}$ of a topological space $(\mathrm{X}, \mathrm{T})$ is strongly compact relative to $(\mathrm{X}, \mathrm{T})$, then the subspace $\left(\mathrm{Y}, \mathrm{T}_{\mathrm{Y}}\right)$ is also strongly compact space.

\section{Proof:}

Let $\mathrm{Y}$ be a T-pre open subset of $\mathrm{X}$ such that $\mathrm{Y}$ is strongly compact w.r.t. topological space $(\mathrm{X}, \mathrm{T})$.

Let $\left(\mathrm{Y}, \mathrm{T}_{\mathrm{Y}}\right)$ be a sub space of $(\mathrm{X}, \mathrm{T})$. We, however, know that if $\mathrm{Y} \epsilon \mathrm{PO}(\mathrm{X}, \mathrm{T})$ and $\mathrm{A} \epsilon \mathrm{PO}\left(\mathrm{Y}, \mathrm{T}_{\mathrm{Y}}\right)$ then $\mathrm{A} \epsilon$ $\mathrm{PO}(\mathrm{X}, \mathrm{T})$. *

Suppose that $\left\{\mathrm{S}_{\alpha}: \alpha \in \Delta\right\}$ be a pre- open cover of $\mathrm{Y}$ w.r.t. the topology $\mathrm{T}_{\mathrm{Y}}$. i.e.

$\mathrm{Y} \subseteq U\left\{\mathrm{~S}_{\alpha}: \alpha \in \Delta\right\}$. 
Clearly, $\left\{\mathrm{S}_{\alpha}: \alpha \in \Delta\right\}$ is also a pre-open cover of $\mathrm{Y}$ w.r.t. topology $\mathrm{T}$ and, here, $\mathrm{Y} \subset \mathrm{X}$ is strongly compact w.r.t . T. This means that there exists a finite subset $\Delta_{0} \subset \Delta$ such that $\left\{\mathrm{S}_{\alpha}: \alpha \in \Delta_{0}\right\}$ is a finite sub cover of the cover $\left\{\mathrm{S}_{\mathrm{a}}: \alpha \in \Delta\right\}$ for $\mathrm{Y}$ in $(\mathrm{X}, \mathrm{T})$.

This means that $\left\{S_{\alpha}: \alpha \in \Delta\right\}$ has a finite sub cover of $Y$ w.r.t. the topology $T_{Y}$.

Consequently, $\left(\mathrm{Y}, \mathrm{T}_{\mathrm{Y}}\right)$ is a strongly compact space.

Hence, the theorem.

Note : the star notation used in the theorem is, here, clarified as:

* Lemma(1.2)(b) as mentioned in "On $\mathrm{P}_{3}$-Para compact spaces", Khalid Al-Zoubi and Samer Al -Ghour, International Journal of Mathematical Sciences, Volume 2007, Article ID80697,12 pages.doi:1155/2007/80697

\section{Remark[3.4]}

A strongly compact subset of a topological space is not necessarily pre-closed.

To see the truth of this remark, let us observe that any finite set in a topological space is strongly compact but it is not necessarily pre closed. For this consider the set $X=\{a, b, c\}$ with topology

$\mathrm{T}=\{\varphi,\{\mathrm{a}\},\{\mathrm{b}\},\{\mathrm{a}, \mathrm{b}\}, \mathrm{X}\}$ so that $\mathrm{T}_{\mathrm{p}}=\{\varphi,\{\mathrm{a}\},\{\mathrm{b}\},\{\mathrm{a}, \mathrm{b}\}, \mathrm{X}\}$. Now, $\{\mathrm{a}\}$ is not pre- closed but strongly p-compact set in $(X, T)$.

A second example showing the validity of the remark is provided by any non empty infinite proper subset $\mathrm{A}$ of a co -finite topological space $(\mathrm{X}, \mathrm{T})$ where $\mathrm{X}$ is infinite $\& \mathrm{~A}^{\mathrm{C}}$ is also infinite. In such a case, $\mathrm{A}$ is a pre open set as well as strongly compact set.

\section{Remark[3.5]}

1. Strongly compactness under pre- continuous mappings or pre- homeomorphism is not invariant. This means that strongly compactness is not a topological property as it is not preserved under pre-homeomorphism.

2. Strongly compactness under pre- irresolute mappings is invariant, showing that it is a topological property.

Theorem (3.6):

If $(X, T)$ is a semi- $T_{2}$ space in which $\mathrm{SO}(\mathrm{X})$ is closed under finite intersection and $\mathrm{A}$ is a semi- compact subset of $\mathrm{X}$, then $\mathrm{A}$ is semi-closed.

Proof:

Suppose that $(X, T)$ is a semi- $\mathrm{T}_{2}$ space in which $\mathrm{SO}(\mathrm{X})$ is closed under finite intersection.

Let $\mathrm{A}$ be the semi- compact subset of $\mathrm{X}$.

Let $x \in A^{C}$. Since, $(X, T)$ is semi- $T_{2}$, for each a $\in A$, there are disjoint semi-open sets $U_{a} \& V_{a}$ containing $\mathrm{x} \&$ a respectively.

Now, $\left\{\mathrm{V}_{\mathrm{a}}: \mathrm{a} \in \mathrm{A}\right\}$ is a semi-open cover of $\mathrm{A}$. Since, $\mathrm{A}$ is semi-compact, this cover has a finite sub-cover, say, $\left\{V_{a_{1}}, V_{a_{2}}, \ldots \ldots . V_{a_{n}}\right\}$. i.e. $A=\bigcup_{r=1}^{n} V_{a_{r}}$.

Let $\mathrm{U}_{\mathrm{x}}=\bigcap_{r=1}^{n} U_{a_{r}}$, then by assumption $\mathrm{U}_{\mathrm{x}}$ is a semi-open set containing $\mathrm{x}$. Also, $\mathrm{U}_{\mathrm{x}} \cap \mathrm{A}=\varphi$ and hence, $\mathrm{U}_{\mathrm{x}} \subseteq \mathrm{A}^{\mathrm{C}}$. Consequently by theorem (1.2), $\mathrm{A}^{\mathrm{C}}$ is semi-open and so $\mathrm{A}$ is semi-closed.

Hence, the theorem.

Theorem (3.7):

A topological space $(\mathrm{X}, \mathrm{T})$ is semi-compact iff every family of semi- closed sets in $\mathrm{X}$ with empty intersection has a finite subfamily with empty intersection .

Proof:

Necessity: Let $(\mathrm{X}, \mathrm{T})$ is a semi- compact space. Let $\left\{F_{\alpha}: \alpha \in \Delta\right\}$ be a family of semi-closed sets in X such that $\bigcap_{\alpha \in \Delta} F_{\alpha}=\phi$. Obviously, $\bigcup_{\alpha \in \Delta} F_{\alpha}^{C}=X$ and $\left\{f_{\alpha}^{C}: \alpha \in \Delta\right\}$ is a semi-open cover of $\mathrm{X}$.

Since, $(\mathrm{X}, \mathrm{T})$ is semi- compact, this cover has a finite sub cover, say $\left\{F_{\alpha_{n}}^{C}: n=1,2, \ldots . p\right\}$ for X. i.e. $\mathrm{X}=\bigcup_{n=1}^{p} F_{\alpha_{n}}^{C}$ which implies that $\phi=\bigcap_{n=1}^{p} F_{\alpha_{n}}$.

Sufficiency: Suppose that every family of semi-closed set in X with empty intersection has a finite subfamily with empty intersection. 
Let $\left\{V_{\alpha}: \alpha \in \Delta\right\}$ be a semi- open cover of (X,T). Then $\bigcup_{\alpha \in \Delta} V_{\alpha}=X$. taking the complements, we get $\bigcap_{\alpha \in \Delta} F_{\alpha}^{C}=\phi$. Since, for each $\alpha \in \Delta, F_{\alpha}^{C} \quad$ is semi-closed set in $\mathrm{X}$, by the assumption, there is a finite subfamily, say, $\left\{V_{\alpha_{n}}^{C}: n=1,2, \ldots . p\right\}$ with empty intersection i.e. $\bigcap_{n=1}^{p} V_{\alpha_{n}}^{C}=\phi$. This implies that $\bigcup_{n=1}^{p} V_{\alpha_{n}}=X$. Hence, $(\mathrm{X}, \mathrm{T})$ is semi-compact.

Now, the behavior of semi-compactness under semi-open onto function and pre-semi-open onto function has been discussed in the following theorems:

Theorem(3.8):

Proof:

If $f:(X, T) \rightarrow(Y, \sigma)$ is a semi-open onto function and $(Y, \sigma)$ is semi-compact, then $(X, T)$ is compact. onto mapping.

Let $(\mathrm{Y}, \sigma)$ be a semi-compact space and $(\mathrm{X}, \mathrm{T})$, any topological space . Let $\mathrm{f}: \mathrm{X} \rightarrow \mathrm{Y}$ be a semi-open Let $\left\{V_{\alpha}\right\}_{\alpha \in \Delta}$ be an open cover for X. Then $\mathrm{X}=\bigcup_{\alpha \in \Delta} V_{\alpha}$

This means that

$$
\begin{aligned}
& \mathrm{f}(\mathrm{X})=f\left(\bigcup_{\alpha \in \Delta} V_{\alpha}\right) \\
& \Rightarrow \mathrm{Y}=\bigcup_{\alpha \in \Delta}\left(f\left(V_{\alpha}\right)\right)
\end{aligned}
$$

Since, f is semi-open mapping, hence, $\left\{f\left(V_{\alpha}\right)\right\}_{\alpha \in \Delta}$ is a semi-

open cover of $Y$.

Again as $(\mathrm{Y}, \sigma)$ is semi-compact as this cover contains finite subcover, namely

$\left\{f\left(V_{\alpha_{1}}\right), f\left(V_{\alpha_{2}}\right), \ldots \ldots, f\left(V_{\alpha_{n}}\right)\right\}$ Such that

$$
\begin{aligned}
& \mathrm{Y}=\bigcup_{r=1}^{n}\left\{f\left(V_{\alpha_{r}}\right)\right\} \\
& \Rightarrow \mathrm{f}^{1}(\mathrm{Y})=\mathrm{f}^{1}\left(\bigcup_{r=1}^{n}\left\{f\left(V_{\alpha_{r}}\right)\right\}\right) \\
& \mathrm{X}=\bigcup_{r=1}^{n}\left\{f^{-1} f\left(V_{\alpha_{r}}\right)\right\} \\
& \Rightarrow \mathrm{X}=\bigcup_{r=1}^{n}\left\{\left(V_{\alpha_{r}}\right)\right\} \\
& \Rightarrow\left\{V_{\alpha_{r}}: r=1,2, \ldots \ldots . n\right\} \text { is a finite subcover of }\left\{V_{\alpha}\right\}_{\alpha \in \Delta} \text { for } \mathrm{X} .
\end{aligned}
$$

$\Rightarrow(\mathrm{X}, \mathrm{T})$ is compact.

Hence, the theorem.

Theorem(3.9):

If $\mathrm{f}:(\mathrm{X}, \mathrm{T}) \rightarrow(\mathrm{Y}, \sigma)$ is a pre-semi-open onto function and $(\mathrm{Y}, \sigma)$ is semi-compact, then $(\mathrm{X}, \mathrm{T})$ is compact.

Proof:

Let $\mathrm{f}:(\mathrm{X}, \mathrm{T}) \rightarrow(\mathrm{Y}, \sigma)$ be a pre-semi-open mapping from a topological space $(\mathrm{X}, \mathrm{T})$ onto a semicompact space $(\mathrm{Y}, \sigma)$.

Let $\left\{V_{\alpha}\right\}_{\alpha \in \Delta}$ be a semi- open cover for $\mathrm{X}$. Then $\mathrm{X}=\bigcup_{\alpha \in \Delta} V_{\alpha}$

$$
\text { This means that } \mathrm{f}(\mathrm{X})=f\left(\bigcup_{\alpha \in \Delta} V_{\alpha}\right)
$$




$$
\Rightarrow \mathrm{Y}=\bigcup_{\alpha \in \Delta}\left(f\left(V_{\alpha}\right)\right)
$$

Since, fis pre- semi-open mapping, hence, $\left\{f\left(V_{\alpha}\right)\right\}_{\alpha \in \Delta}$ is a semi-open cover of Y. Again as $(\mathrm{Y}, \sigma)$ is semicompact, so this semi-open cover has a finite sub-cover, namely $\left\{f\left(V_{\alpha_{1}}\right), f\left(V_{\alpha_{2}}\right), \ldots \ldots ., f\left(V_{\alpha_{n}}\right)\right\}$ such that $\mathrm{Y}=\bigcup_{r=1}^{n}\left\{f\left(V_{\alpha_{r}}\right)\right\}$

Hence, the theorem.

$$
\begin{gathered}
\Rightarrow \mathrm{f}^{1}(\mathrm{Y})=\mathrm{f}^{1}\left(\bigcup_{r=1}^{n}\left\{f\left(V_{\alpha_{r}}\right)\right\}\right) \\
\Rightarrow \mathrm{X}=\bigcup_{r=1}^{n}\left\{f^{-1} f\left(V_{\alpha_{r}}\right)\right\} \\
\Rightarrow \mathrm{X}=\bigcup_{r=1}^{n}\left\{\left(V_{\alpha_{r}}\right)\right\} \\
\Rightarrow\left\{V_{\alpha_{r}}: r=1,2, \ldots \ldots . . . n\right\} \text { is a finite sub cover of }\left\{V_{\alpha}\right\}_{\alpha \in \Delta} \text { for } \mathrm{X} . \\
\Rightarrow(\mathrm{X}, \mathrm{T}) \text { is compact. }
\end{gathered}
$$

\section{Definition (3.10): Countably a-compact:}

A topological space $(\mathrm{X}, \mathrm{T})$ is said to be countably $\alpha$-compact(or to have $\alpha$-Bolzano Weierstrass property) iff every infinite subset of $\mathrm{X}$ has at least one $\alpha$ - limit point in $\mathrm{X}$.

Or

A topological space $(\mathrm{X}, \mathrm{T})$ is known as countably $\alpha$-compact iff every countable $\mathrm{T}$ - $\alpha$-open cover of $\mathrm{X}$ has a finite sub- cover.

\section{Definition(3.11): Sequentially $\alpha$-compact spaces:}

A topological space $(\mathrm{X}, \mathrm{T})$ is said to be sequentially $\alpha$-compact iff every sequence in $\mathrm{X}$ contains a subsequence which is $\alpha$ - convergent toa point of $X$.

Theorem(3.12):

As an illustration, every finite subspace of a topological spaceis sequentially $\alpha$-compact.

Proof:

Every sequentially $\alpha$-compact topological space $(\mathrm{X}, \mathrm{T})$ is countably $\alpha$-compact .

Let $(\mathrm{X}, \mathrm{T})$ be a sequentially- $\alpha$ - compact topological space. Let $\mathrm{E}$ be an infinite subset of $\mathrm{X}$. Then there exists an infinite sequence $\left\{\mathrm{x}_{\mathrm{n}}\right\}$ in $\mathrm{E}$ with distinct terms.

Since $(X, T)$ is sequentially- $\alpha$ - compact, the sequence $\left\{x_{n}\right\}$ contains a sub sequence $\left\{x_{n k}\right\}$ which is $\alpha$ convergent to $\mathrm{x}_{0} \in \mathrm{X}$.

This means that each $\alpha$-open set containing $\mathrm{x}_{0}$ contains an infinite number of elements of $\mathrm{E}$.

Hence, $x_{0}$ is an $\alpha$-accumulation point of $E$.

Thus, every infinite subset of X has at least one $\alpha$-accumulation point in X. Consequently(X,T) is countably $\alpha$-compact.

Therefore, sequentially $\alpha$-compactness implies countable $\alpha$-compactness.

Hence, the theorem.

\section{Remark(3.13):}

The converse statement "A countably $\alpha$-compact space is sequentially $\alpha$-compact." is not true as illustrated by following example:

Let $\mathrm{N}=\{\mathrm{n}: \mathrm{n}$ is a natural number $\}$.

Let $T$ be topology on $N$ generated by the family $H=\{\{2 n-1,2 n\}: n \in N\}$ of subsets of $N$.

Let $\mathrm{E}$ be a non-empty subset of $\mathrm{N}$.

Let $\mathrm{m}_{0} \in \mathrm{E}$. If $\mathrm{m}_{0}$ is even $\mathrm{m}_{0}-1$ is an $\alpha$-accumulation point of $\mathrm{E}$ and if $\mathrm{m}_{0}$ is odd $\mathrm{m}_{0}+1$ is an $\alpha$-accumulation point of E. Hence, every non-empty subset of $\mathrm{N}$ has an $\alpha$-accumulation point, so that $(\mathrm{N}, \mathrm{T})$ is countably $\alpha$-compact.

Also, the family $\mathrm{H}$ is a $\alpha$-open covering of $\mathrm{N}$ which is not reducible to any finite subcovering of $\mathrm{N}$. Hence, $(\mathrm{N}, \mathrm{T})$ is not $\alpha$-compact. sub-sequence.

Again, $(N, T)$ is not sequentially $\alpha$-compact because the sequence $\{2 n-1: n \in N\}$ has no $\alpha$-convergent Therefore,

Countably $\alpha$-compactness $\nRightarrow \alpha$-sequentially compactness. 
Theorem(3.14):

$\nRightarrow \alpha$-compactness.

A $\alpha$-continuous image of a sequentially $\alpha$-compact set is sequentially compact.

Proof:

Suppose, $\mathrm{f}$ is a $\alpha$-continuous mapping. Let $\mathrm{A}$ be a sequentially $\alpha$-compact set of $\mathrm{X}$ and we have to show that $\mathrm{f}(\mathrm{A})$ is sequentially compact subset of $\mathrm{Y}$.

Let $\left\{\mathrm{y}_{\mathrm{n}}\right\}$ be an arbitrary sequence of points in $\mathrm{f}(\mathrm{A})$, then for each $\mathrm{n} \in \mathrm{N}$ there exists $\mathrm{x}_{\mathrm{n}} \in \mathrm{A}$ such that $\mathrm{f}\left(\mathrm{x}_{\mathrm{n}}\right)$ $=\mathrm{y}_{\mathrm{n}}$ and thus we obtain a sequence $\left\{\mathrm{x}_{\mathrm{n}}\right\}$ of points of $\mathrm{A}$.

But $\mathrm{A}$ is sequentially $\alpha$-compact w.r.t. T so that there is a subsequence $\left\{\mathrm{x}_{\mathrm{nk}}\right\}$ of $\mathrm{A}$ which is $\alpha$-compact to a point say, $\mathrm{x}$ of $\mathrm{A}$.

Therefore, $x_{n k} \stackrel{\alpha-c g t}{\longrightarrow} x \Rightarrow f\left(x_{n k}\right) \rightarrow f(x) \in f(A)$ as $\mathrm{f}$ is $\alpha$-continuous.

Hence, $f\left(x_{n k}\right)$ is a subsequence of the sequence $\left\{y_{n}\right\}$ of $f(A)$, converging to a point $f(x)$ in $f(A)$. Consequently, $\mathrm{f}(\mathrm{A})$ is sequentially compact.

\section{Corollary (3.15):}

The $\alpha$-irresolute image of a sequentially $\alpha$-compact set is a sequentially $\alpha$-compact. This means that sequentially $\alpha$ - compactness is a topological property under $\alpha$-irresolute mapping.

Definition(3.16): $\mathrm{C}_{1}$-space:

A space $(X, T)$ is said to be $\quad C_{1}$ space if every infinite subset of $X$ has a non-empty interior .i.e. $\left[(X, T)\right.$ is a $C_{1}$ space $] \Leftrightarrow[$ for any $A \subseteq X, T-i n t(A)=\varphi \Rightarrow A$ is finite $]$.

Definition(3.17): $\mathrm{C}_{2}$-space: $\neq \varphi$. i.e.

A space $(X, T)$ is said to be $\quad C_{1}$ space if every infinite subset $S$ of $X$ is such that $T$-int(T-cl $\left.S\right)$

$\left[(\mathrm{X}, \mathrm{T})\right.$ is a $\mathrm{C}_{2}$ space $] \Leftrightarrow[$ for any $\mathrm{A} \subseteq \mathrm{X}, \mathrm{T}-\operatorname{int}(\mathrm{T}-\mathrm{cl} \mathrm{A})=\varphi \Rightarrow \mathrm{A}$ is finite $]$.

Definition (3.18): FCC:

A space $(X, T)$ satisfies the "finite chain condition" abbreviated FCC, if every disjoint family of nonempty open sets is finite.

Illustration :

The co-finite topological space $(X, T)$ on the infinite ground set $\mathrm{X}$ is a $\mathrm{C}_{2}$ space but not a $\mathrm{C}_{1}$ space.

Now, Maximilhian Ganster establish the following theorems in "Some Remark On Strongly Compact Spaces And Semi-Compact spaces.”, appeared in Bull.Malaysian Math. Soc.(10)2(1987),67-81.

Theorem [3.19]:

For a space $(X, T)$ let $I_{x}$ be the set of isolated points of $(X, T)$. Then $(X, T)$ satisfies $\left(C_{1}\right)$ if and only if $\mathrm{X} \backslash \mathrm{I}_{\mathrm{X}}$ is finite.

Theorem [3.20]:

Concluding remark:

A space $(X, T)$ is semi-compact if and only if it satisfies both $\left(\mathrm{C}_{2}\right)$ and FCC.

Since pre-open sets \&semi-open sets of a topological space $(X, T)$ are already $\beta$-open sets, every $\beta$ compact space has to be strongly compact and semi-compact.

Now, if $(X, T)$ is an infinite strongly compact space, the set $I_{x}$ of the isolated points of $(X, T)$ is finite by theorem[3.19]. It follows that (X,T) does not satisfy FCC and so is not semi-compact by theorem[3.20].

Consequently, infinite $\beta$-compact space do not exist. i.e. every $\beta$-compact space is finite. $\boldsymbol{*}$

*

M.Ganster, “Every $\beta$-compact space is finite.” Bull.Calcutta Math. Soc., 84(1992),287-288.

\section{Observations \& Conclusions(3.21):}

1(a) Every p-compact (i.e. strongly compact spaces), s-compact or $\alpha$-compact space is compact but converse is not true.

(b)Every $\beta$-compact space is finite and a finite space is always compact. So, a $\beta$-compact space is a finite compact space. Also every finite space is $p$-compact, s-compact, $\alpha$-compact.

2(a) Every semi-compact sub-space of a p-compact space is p-compact as a subspace. i.e. p-compactness is hereditary w.r.t. semi-open set.

(b)Every sub-space of a s-compact space is semi-compact as a subspace. i.e. s-compactness is hereditary.

(c) $\alpha$-compactness as well as $\beta$-compactness is hereditary.

3.(a) $\kappa$-compactness is invariant under $\kappa$-irresolute surjective mapping but not invariant under $\kappa$-continuous surjective mapping where $\kappa=\mathrm{p}, \mathrm{s}, \alpha \& \beta$.

(b) $p, s, \alpha \& \beta$-compactness is a topological property under $\mathrm{p}, \mathrm{s}, \alpha \& \beta$-irresolute surjective mapping.

(c) sequentially $\alpha$-compactness is not a topological property under $\alpha$-continuous surjective mapping. 
4(a) A topological space is a p,s, $\alpha$-compact iff every collection of $p, s, \alpha$-closed subsets of the space with FIP is "fixed".

(b) A topological space is a p,s, $\alpha$-Lindelöf iff every family of $\mathrm{p}, \mathrm{s}, \alpha$-closed sets of the space with CIP is "fixed".

(c) A $\alpha$-Lindelöf space need not be a $\alpha$-compact space.

(d) A second countable $\alpha$-space is a $\alpha$-Lindelöf space.

5(a) A space is p-compact iff it is both a $\mathrm{C}_{1}$-space \& a compact space.

(b)A space is s-compact iff it is both a $\mathrm{C}_{2}$-space \& a s-closed space.

Recall that a space $(\mathrm{X}, \mathrm{T})$ is s-closed iff every cover of $\mathrm{X}$ by regular closed subsets has a finite subcover.

(c)A sequentially $\alpha$-compact space is countably $\alpha$-compact but the converse is not true.

Countably $\alpha$-compactness $\nRightarrow \quad \alpha$-sequentially compactness. $\nRightarrow \quad \alpha$-compactness.

\section{References:}

[1]. Andrijevic, D., : semi-pre open sets, Mat. Vesnik, 38, no.1, 24-32(1986).

[2]. Balachandran, K., Sundaram, P. and Mack, H., : On generalized continuous maps in topological spaces, Mem. Fac. Sci., Kochi Univ. Ser. A, Math., 12, 5-13(1991).

[3]. Njastad,O; On Some Class Of Nearly Open Sets, Pacific J.Math., (15)(1965), 961-970,

[4]. Devi,R. and Bhuwaneshwari, K., : $\alpha$-weekly generalized closed sets in bitopological spaces, Acta ciencia Indica, Vol .30, 2004 pp, 167-172.

[5]. Devi, R., Mack, H. \& Balachandran, K., : Semi-generalized closed maps and generalized semi closed maps, Mem. Fac. Sci., Kochi Univ. Ser. A, Math, 14, 41-54(1993).

[6]. EI-Deeb, S.N., M.E.abd EI-Monsef \& Mahmoud,R.A., : $\beta$-open sets and $\beta$-continuous mappings, Bull. Fac. Sci. Assiut. Univ., $12,77-90(1983)$

[7]. Mohammad S. Sarsak, On Semi-compact Sets and Associated Properties, International journal of mathematics and mathematical Science Volume 2009(2009), Article ID 465387, 8 pages.

[8]. Anderjevic.D : on b-open sets, Mat Vesnik 48(1996)p.p.59-64.

[9]. Andrijevic,D., some properties of the topology of $\alpha$ - sets, Mat ,Vesnik 36 (1984),p.p 1-10).

[10]. Khalid Al-Zoubi and Samer Al -Ghour,On $\mathrm{P}_{3}$-Para compact spaces, International Journal of Mathematical Sciences, Volume 2007, Article ID80697,12 pages.doi:1155/2007/80697.

[11]. Dontchev,J., "Survey on pre open sets", arXiv: math. GN/ 9810177, Vol. 30,Oct., (1998).

[12]. M. K. R. S. Veera Kumar, “Pre semi - closed sets”, Indian Journal of Mathematics, Vol. 44, No.2, (2002), 165 - 181.

[13]. A. S. Mashhour, M.E. Abd- El- Monsef and S.N. El- Deeb, “ On Pre- continuous andweak Pre- continuous Mappings", Proc. Math. and phys. Soc. Egypt 53(1982), 47-53.

[14]. S.N.El-Deeb ,I.A.Hasanein, A.S.Mashhour and T.Noiri, On p-regular spaces, Bull . Math.de la Soc.Sci. Math.(R.S.R),Tome 27(75)(4)(1983), 311-315.

[15]. A.S.Mashhour, M.E.Abd El-Monsef and I.A.Hasanein , On pre topological spaces, Bull.Math. Soc.Sci. Math.,R.S.R., 28(76)(1984),39-45.

[16]. Navalagi, G.B.,Pre-neighbourhoods, The Mathematics Education , (1998), 201-206.

[17]. Popa,V., Characterizations of H-almost continuous functions, Glasnik Mat. Vol.22(42)(1987), 157-161.

[18]. A.S.Mashhour,M.E.Abd El-Mousef, I.A.Hasanein and T.Noiri, “strongly compact spaces” Delta J. Sci. 8(1)(1984),30-46.

[19]. Dorsett,C. Semi compactness, semi separation axioms, and product spaces, Bull.Malaysian Math. Soc. (2) 4 (1981), 21-28.

[20]. Dorsett, C.Semi convergence and semi compactness, Indian J. Mech. Math. 19 (1)(1982), 11-17.

[21]. Hanna,F. and Dorsett, C.,Semi compactness, Q \& A in General Topology 2 (1984),38-47.

[22]. Ganster,M., "Every $\beta$-compact space is finite." Bull.Calcutta Math. Soc., 84(1992),287-288.

[23]. Maximilhian Ganster "Some Remark On Strongly Compact Spaces And Semi-Compact spaces.",appeared in Bull.Malaysian Math. Soc.(10)2(1987),67-81 